\title{
Engineering Outreach Using a Hands-On Case Study Approach
}

\author{
Martin Scherer*, Lindsay Brock**, and Steve Lambert*** \\ Faculty of Engineering, University of Waterloo, Ontario Canada
}

\section{INTRODUCTION}

University-led outreach programs have been active in Canada for over 20 years. Today, more than 200,000 students participate in these programs with a variety of activities such as camps, workshops, and community outreach programs [1]. Almost three quarters of these students participated in workshops, including in-class led by teachers with materials provided by Universities as well as on-campus activities.

At the University of Waterloo, the Engineering Science Quest (ESQ) program has been running for 20 years to expose elementary school children to hands-on science and engineering. The goals of the program are to excite children about science, technology, engineering and math (STEM), and to show them through hands-on activities that these can be directly applied to solve real-world problems. A secondary goal is to improve their scientific, engineering and technological literacy [2]. Al activities are designed to complement the Ontario elementary school curriculum. About 2200 students participate in ESQ, in over 100 oneweek sessions, each summer. ESQ runs a further 200 workshops in elementary classrooms.

Until recently, Waterloo did not run workshops designed for a high school audience. The focus to date of ESQ activities has been on elementary school audiences, to promote continued interest in science and engineering. For the older high school audience, a need was identified to more strongly reflect the work done in a post-secondary environment. This has been done through participation in First Robotics, and recent 'Designing the Future' events, wherein students are exposed to engineering design through a combination of hands-on design exercises, lectures, and displays of University student projects. To further develop these workshops, the Outreach group has joined forces with the Waterloo Cases in Design Engineering (WCDE) group to integrate more realistic contexts and computer simulations into these activities.

\section{Waterloo Cases in Design Engineering}

The WCDE group was formed as part of Waterloo's NSERC Chair in Design Engineering. They are focused on the generation of real-world case studies, to be used in various ways in classes throughout the engineering curriculum. Cases are an effective way to bring the complexity of everyday engineering problems into the class environment, and thereby to help students develop important professional skills of judgment, design and the application of engineering science.

A key problem with such an approach is the generation of a critical mass of case studies which cover a diverse range of engineering disciplines and concepts. At Waterloo, this challenge has been met by using our own students work term reports as the basis for engineering case studies [3]. This provides a sustainable supply of cases covering a diverse range of technical areas. To date, WCDE has generated over 40 case studies, and is on track to generate $30-45$ cases per year. In addition to cases developed from work term reports, WCDE develops and implements cases directly from our partners, including Engineers Without Borders (www.ewb.ca).

\section{High School Workshops}

Since most students know where they will ultimately go after high school (further study of arts or STEM, entering the workforce), the focus of high school workshop programming must reflect this fact. Thus the goal is no longer about creating interest in STEM, but instead about keeping interest, and providing a better idea of what it is like to study STEM at a post-secondary level, and how these skills can make a positive impact in the world.

With this in mind, it was decided that three principles would be used to identify a successful high school workshop.

1. Have multiple hands-on components: a building challenge and a simulation to help ignite interest in multiple learning styles; each activity building on the other to build a stronger picture of engineering.

2. Real world connections and to show that engineering applications are more than what is traditionally viewed, such as making bridges and cars.
3. Modular in design, to allow greater focus on a given part, dictated by the class' ability and interest; if time is limited, the building or simulation components should be able to stand on their own.

Recently, a workshop was developed following these principles, based on a case study developed by Engineers Without Borders. This case was repackaged by the WCDE group and has been used in first year introduction to Engineering courses across the Faculty to introduce students to the design process, and the role of simple order-of-magnitude calculations and then more detailed simulations in that process. Engineering students have been led through the development of the simulation tool as part of the process. This case was seen as an ideal starting point since the material was accessible to a high school audience, and was able to illustrate the role of math, science, and engineering simulations in engineering design.

The new workshop had two complementary modules: a design/build module, and a simulation module. These could be run on consecutive days, but in either sequence, to maximize flexibility, and to investigate alternate learning modes.

Design/Build:

The design/build module was focused on the construction of the least expensive model roof to collect the most rainwater. Students were given a set of materials from which to choose, a price list, and a budget. Each material had a unique cost/benefit. For example, a plastic sheet is durable and absorbs water less than cardboard, but costs more. Rainwater was simulated using a predetermined amount of water from a garden can. Project success was based on cost and collection efficiency. Simulation:

Several simulations were developed using a spreadsheet program. These simulations were provided to the students and their operation discussed. Thus the focus of the exercise was on the use of the simulation tool, not its development. This use included selection of the best data set to use, selecting storage tank size and material, investigation of the impact of family size on water needs and cost, and simulated performance over a 10 year period.

\section{Results and Further Work}

This workshop allowed students to experience the various trade-offs necessary: between construction costs and performance, design versus build time, and technical trade-offs such as roof versus storage tank size. They were directly able to experience the need in engineering to use judgment and to work as a team. To date, the workshop has been run a handful of times, with focus on one or the other module. Students of diverse backgrounds (aboriginal communities and urban) have provided positive feedback on their experience. Going forward, it is intended to offer this workshop to more students, using both modules, and to obtain more formal feedback.

Further work is ongoing on the development of case studies directly focused on high school students. Cases related to climate change and carbon footprint have been requested by local high school teachers. A case is in development using a combination of a mechanical dissection project of small mechanical devices (toys), and the use of online tools to identify their carbon footprint, including manufacturing, distribution, and operating phases of use. This will be expanded to look at the analogous water footprint of materials, including foods.

\section{REFERENCES}

1. Actua, "Focus on Possibilities", annual report, 2009-2010, www.actua.ca.

2. M. Scherer and M. Wells, "How to Measure Success in University Led Engineering Outreach Programs for Elementary School Children", Canadian Engineering Education Conference, Kingston, Ontario, June 79, 2010.

2. S. Lambert, C. Campbell, and O. Nespoli, "Leveraging Student Co-op Design Experience Using Case Studies", International Conference on Engineering and Product Design Education, Universitat de Catalunya, Barcelona, Spain, 4-5 September, 6 pages (2008).

\section{AFFILIATED INSTITUTIONS FOR CO-AUTHORS * Manager of Engineering Outreach **Nanotechnology Undergraduate Co-op Student for WCDE ***NSERC - Waterloo Chair in Design Engineering}

